\title{
Beliefs about memory decline in aging do not impact judgments of learning (JOLs): A challenge for belief-based explanations of JOLs
}

\author{
Sarah K. Tauber ${ }^{1} \cdot$ Amber E. Witherby ${ }^{1} \cdot$ John Dunlosky ${ }^{2}$
}

Published online: 11 March 2019

(C) The Psychonomic Society, Inc. 2019

\begin{abstract}
The cue-utilization framework (Koriat, 1997) and the analytic processing theory (Dunlosky, Mueller, \& Tauber, 2015) identify people's beliefs about their memory as central to how judgments of learning (JOLs) are made. This assumption is supported by ample evidence. However, researchers have almost exclusively explored the impact of participants' beliefs about the materials or the learning task, and none have evaluated the impact of beliefs about a person on JOLs. Thus, to inform JOL theory, we evaluated the degree to which JOLs are related to the belief that "memory declines with aging in adulthood." In seven experiments, college-aged participants studied words, made JOLs, and took a memory test. Participants made JOLs predicting memory performance for an average younger adult (i.e., 18-21 years old) or for an average older adult (i.e., 65+ years old). Most important, beliefs about aging in adulthood were not always sufficient to produce cue effects on JOLs, which contrasts with expectations from the aforementioned theories. An important challenge for future research will be to discover factors that moderate belief effects. To guide such explorations, we discuss possible explanations for why beliefs about aging would have demonstrated little to no relationship with people's JOLs.
\end{abstract}

Keywords Metacognitive beliefs $\cdot$ Judgments of learning $\cdot$ Aging $\cdot$ Emotion $\cdot$ Retrospective-global judgments

Contemporary theories of metacognitive monitoring propose that people's beliefs about their memory influence their judgments of learning (JOLs; e.g., Koriat, 1997; Mueller \& Dunlosky, 2017). Consistent with these theories, convincing evidence is available that beliefs do impact people's JOLs (for a review, see Dunlosky, Mueller, \& Tauber, 2015). For instance, people typically believe that related pairs of words (e.g., loaf-bread) will be remembered better than unrelated pairs (e.g., cup-bread), and this belief apparently makes a substantial contribution to the relatedness effect, wherein people give higher JOLs to related than to unrelated pairs (Mueller, Tauber, \& Dunlosky, 2013; for evidence that nonbelief factors may also contribute to this effect, see, e.g., Besken \& Mulligan, 2013; Susser \& Mulligan, 2015; Undorf \& Erdfelder, 2015). However, few studies have

Sarah K. Tauber

uma.tauber@tcu.edu

1 Department of Psychology, Texas Christian University, Fort Worth, TX, USA

2 Department of Psychological Sciences, Kent State University, Kent, OH, USA systematically investigated the contribution of beliefs to JOLs (e.g., Frank \& Kuhlmann, 2017; Mueller \& Dunlosky, 2017), and consequently, current theories of JOLs have not been fully vetted with respect to how they explain the relationship between beliefs and JOLs. In prior studies, researchers have largely investigated the influence of people's beliefs about the materials or the learning task. Do people's beliefs about individual differences (e.g., aging in adulthood) also impact JOLs? And, more generally, does any belief about memory influence JOLs?

To address these (and other) questions, the primary goal of the present research was to evaluate whether people's beliefs about aging and memory will impact their JOLs. In the remainder of this introduction, first we describe the outcomes that demonstrate the contribution of beliefs to how people make JOLs. Then we describe two theories of JOLs, both of which implicate beliefs as central to how people construct JOLs.

\section{Contribution of beliefs to judgments of learning}

Recent research has established that people's beliefs about the impact of a cue can influence their JOLs (e.g., Hu et al., 2015; 
Jia et al., 2016; Mueller \& Dunlosky, 2017; Mueller, Dunlosky, \& Tauber, 2016; Mueller, Dunlosky, Tauber, \& Rhodes, 2014; Mueller, Tauber, \& Dunlosky, 2013; Susser, Jin, \& Mulligan, 2016; Undorf \& Zimdahl, 2019; Witherby $\&$ Tauber, 2017). One way that this contribution of memory beliefs has been evaluated is with questionnaires probing for people's beliefs about their memory (Besken, 2016; Jia et al., 2016; Koriat, Bjork, Sheffer, \& Bar, 2004; Kornell, Rhodes, Castel, \& Tauber, 2011; Li, Jia, Li, \& Li, 2016; Li et al., 2017; Mueller et al., 2016; Mueller, Dunlosky, Tauber, \& Rhodes, 2014; Mueller et al., 2013; Price, McElroy, \& Martin, 2016; Witherby \& Tauber, 2017, 2018).

As one example, Witherby and Tauber (2017) used a questionnaire to explore people's beliefs about the impact of word concreteness on memory. Participants read a hypothetical experiment in which students learned a list of concrete words (e.g., table) and abstract words (e.g., loyalty) and received a memory test. Participants estimated that the hypothetical students would remember more concrete than abstract words, which demonstrates a belief that concreteness impacts memory. As important, in a follow-up experiment, word concreteness impacted participants' JOLs in accord with their beliefs, in that JOLs were higher for concrete than for abstract words. Similar outcomes have been obtained with other cues, such as word frequency (Jia et al., 2016), font size (Mueller et al., 2014), word animacy (P. Li et al., 2016), size of mental images (T. Li et al., 2017), and word pair relatedness (Mueller et al., 2013). Typically, when participants demonstrate beliefs about a cue, the cue also influences JOLs (see the General Discussion for a few exceptions), which together confirm the general hypothesis that participants' beliefs about a cue are used to construct JOLs.

\section{Theories about judgments of learning}

Consistent with the outcomes discussed above, people's beliefs about their memory are a core part of contemporary theories of JOLs. The cue-utilization framework claims that JOLs are inferential and can be based on a number of available cues (Koriat, 1997). A component of this theory categorizes cues as either intrinsic or extrinsic. Intrinsic cues are characteristics inherent to the to-be-learned items that provide information about item memorability, such as word pair relatedness, concreteness, or valence. Extrinsic cues are specific to the learning task, such as the retention interval between study and test or the strategies applied by the learner. Most relevant for the present purposes, the cue-utilization framework (Koriat, 1997) indicates that both kinds of cue (intrinsic and extrinsic) can impact JOLs through explicit analytic processing, which refers to consciously applying a belief about a cue in order to analytically construct a JOL. Similarly, the analytic processing (AP) theory (Dunlosky et al., 2015) emphasizes that when asked to make JOLs, people search for cues that they believe will impact their memory. These cues are used to make JOLs, in an attempt to reduce uncertainty about whether the judged items will be remembered. ${ }^{1}$ In contrast with the cue-utilization account, the kind of cue (whether intrinsic or extrinsic) is not important with respect to whether a cue will impact JOLs. Instead, AP theory emphasizes that whether a person has a belief about a particular cue is what matters. Despite such differences, both theories predict that people's beliefs about how aspects of the learning task impact memory will influence their JOLs.

\section{Present approach to evaluating the theoretically motivated predictions}

In the present research, we focus on a kind of belief that is novel in the JOL literature - namely, beliefs about the impact of a person characteristic on memory. Most people believe that aging in adulthood negatively influences episodic memory. Lineweaver and Hertzog (1998) measured people's beliefs about memory from participants who were 18-93 years old. Of most interest, participants judged the memory ability of people across the lifespan. To do so, they were provided with a continuum from very good to very poor and drew a line to represent the memory ability of the people in each age group (e.g., 20-year-olds, 30-year-olds, etc.). Participants provided their beliefs about global memory ability (i.e., the ability to remember things generally) and about specific memory ability (e.g., memory for faces, trivia, or grocery lists). In all cases, participants' judgments indicated the belief that memory is negatively impacted by aging. As the authors noted, "On average, adults of all ages believe that memory declines across the adult life span, with accelerating decline in the second half of adulthood" (Lineweaver \& Hertzog, 1998, p. 288). Such beliefs are perhaps not surprising, because aging in adulthood can have a deleterious effect on memory (for reviews, see Hertzog \& Hultsch, 2000; Hoyer \& Verhaeghen, 2006).

To gather a more contemporary view of people's beliefs about memory decline in aging, we assessed them with a population used in the present study (i.e., younger adults). As we previously noted, questionnaires that include a description of prior (or hypothetical) experiments are a common method to investigate the contribution of participants' beliefs to JOLs. As such, 43 Kent State University students were recruited from two classes (Introduction to Psychology, $n=$ 24; Personality, $n=19$ ). At their own pace, participants completed the paper-and-pencil questionnaire (see the Appendix),

\footnotetext{
${ }^{1}$ Although both perspectives (i.e., AP theory and the cue-utilization framework) implicate an effect of fluency on JOLs (for details, see Dunlosky et al., 2015; Koriat, 1997), our focus is on people's beliefs and not on the impact of processing fluency. Nevertheless, we do consider the fluency component of these theories in the General Discussion.
} 
on which they were asked, "Do you think aging influences memory? That is, does people's ability to learn new information decline as they become 65 years or older?" with "yes" and "no" response options. Most participants $(81 \%)$ indicated the belief that the ability to learn new information declines with age (i.e., 34 participants responded "yes," and one participant did not respond). Participants' responses did not differ between classes (Introduction, $n=20$ "yes" responses, which was 83\% of the group; Personality, $n=14$ "yes" responses, which was $74 \%$ of the group), $\chi^{2}(2, N=43)=1.50, p=.47$. Participants were also provided with a hypothetical experiment with the task to make a global estimate about performance for an older adult and a younger adult. These differentiated global estimates reflect people's beliefs (Dunlosky \& Hertzog, 2000), and estimates were significantly lower for the older adults $(M=45.0 \%$, $S E=2.7)$ than for the younger adults $(M=58.1 \%, S E=2.6)$, $F(1,41)=40.35, p<.001, \eta_{\mathrm{p}}^{2}=.50$. Participants' estimates did not differ between classes [Introduction, $M_{\text {old }}=49.7, S E=3.5$, $M_{\text {young }}=62.4, S E=3.4$; Personality, $M_{\text {old }}=40.2, S E=4.0$, $\left.M_{\text {young }}=53.8, S E=3.8, F(1,41)=3.55, p=.07, \eta_{\mathrm{p}}{ }^{2}=.07\right]$, and class did not interact with the judgment group $(F<1)$. Thus, consistent with Lineweaver and Hertzog (1998), aging had a large effect on people's estimates, with participants predicting that an older adult would remember less than a younger adult (cf. Ryan, 1992; Ryan \& See, 1993).

Even so, it is not clear whether participants' beliefs about memory decline in aging will affect their item-byitem JOLs. The prediction from both the cue-utilization perspective and AP theory is straightforward: People's beliefs about the impact of aging on memory will directly influence their JOLs, with the magnitude of the JOLs being lower when they are made for an older adult than for a younger adult. Nevertheless, the previous research on beliefs and JOLs has focused primarily on characteristics of the to-be-learned information (see Table 1). In particular, most researchers have evaluated participants' beliefs about the impact of (a) different types of words and (b) how the words are presented. In only a few cases have researchers investigated other kinds of cue (e.g., number of study opportunities or retention interval), and these cues were directly relevant to the learning task itself and do not necessitate taking another's perspective. By contrast, taking another person's perspective might be essential when considering the impact of any person characteristic (e.g., age, gender, IQ) on memory. Thus, whether people use their beliefs about memory decline in aging when they make JOLs is unclear.

\section{Experiment 1}

Participants in Experiment 1 studied a list of words, and for each word they made a JOL predicting memory performance for another person. Some of the participants made JOLs predicting memory performance for an average person between the ages of 18 and 21 (i.e., a younger adult), and other participants made JOLs predicting memory performance for an average person who was 65 years or older (i.e., an older adult). ${ }^{2}$ Additionally, participants studied words that were neutral (e.g., fabric) or negative (e.g., slum) in valence (cf. Tauber \& Dunlosky, 2012; Zimmerman \& Kelley, 2010). Though it was not of primary interest, valence was manipulated because participants might have beliefs about how aging influences memory for emotional information. For instance, the socio-emotional selectively hypothesis (e.g., Carstensen, 1993, 1995; Mather \& Carstensen, 2005) suggests that younger adults focus on negative experiences, whereas older adults prefer to focus on more positive experiences. From this perspective, participants may predict that a younger adult would remember negative items better than neutral items, but that an older adult would remember neutral items better than negative items. Most important, according to the cue-utilization framework and AP theory, JOLs will be lower when they are made for an older adult relative to a younger adult.

In Experiment 1 (and in the experiments that follow), participants also made retrospective-global judgments, which were made after the test by estimating the number of words that a younger adult would have remembered or by estimating the number of words that an older adult would have remembered. Including these judgments allowed us to investigate the impact of participants' beliefs about cognitive decline with age on two distinct types of metacognitive judgments. Specifically, retrospective-global judgments are made by aggregating the entire study-test sequence experience, whereas JOLs are item-by-item and prospective in nature. Thus, even though the present research was focused on participants' JOLs, the analyses of retrospective-global judgments might aid in interpreting the JOL outcomes.

\section{Method}

Design and participants A 2 (judgment group: younger adult vs. older adult) $\times 2$ (word type: negative vs. neutral) mixed design was used, with judgment group manipulated betweenparticipants and word type manipulated within-participants. Sixty-four undergraduate students were recruited from the Department of Psychological Sciences subject pool at Kent State University. This subject pool includes students enrolled in intro-level psychology courses with the requirement to participate in research, and students who have the option to participate

\footnotetext{
${ }^{2}$ We also conducted other experiments in which younger adults made selfjudgments or judgments for an average older adult, an average younger adult, or an older adult with Alzheimer's disease. The outcomes involving average younger versus older adults were consistent with conclusions based on the outcomes from the present experiments, and we will report those experiments (which focus on beliefs about the impact of Alzheimer's disease on memory) in a forthcoming article.
} 
Table 1 Cues for which people's beliefs have been measured and JOLs have been investigated

\begin{tabular}{|c|c|c|c|}
\hline Cue & Example or Explanation & Measure of Beliefs & Source(s) \\
\hline \multicolumn{4}{|l|}{ Types of Words or Images } \\
\hline Word frequency & $\begin{array}{l}\text { High Frequency: cat } \\
\text { Low Frequency: raccoon }\end{array}$ & $\begin{array}{l}\text { Survey, } \\
\text { Prestudy JOLs }\end{array}$ & Jia et al. (2016) \\
\hline Concreteness & $\begin{array}{l}\text { Concrete: table } \\
\text { Abstract: loyalty }\end{array}$ & $\begin{array}{l}\text { Survey, } \\
\text { Prestudy JOLs }\end{array}$ & Witherby \& Tauber (2017) \\
\hline Animacy & $\begin{array}{l}\text { Animate: panda } \\
\text { Inanimate: curtain }\end{array}$ & Survey, & P. Li et al. (2016) \\
\hline Relatedness & $\begin{array}{l}\text { Related pair: pasture-cow } \\
\text { Unrelated pair: salt-mayor }\end{array}$ & $\begin{array}{l}\text { Survey } \\
\text { Prestudy JOLs }\end{array}$ & $\begin{array}{l}\text { Dunlosky et al. (2015), Mueller et al. (2016), Mueller et al. } \\
\text { (2013), Price \& Harrison (2017) }\end{array}$ \\
\hline Identical word Pairs & $\begin{array}{l}\text { Identical pair: cow-cow } \\
\text { Related pair: pasture-cow } \\
\text { Unrelated pair: ace-cow }\end{array}$ & $\begin{array}{l}\text { Survey, } \\
\text { Prestudy JOLs }\end{array}$ & Mueller et al. (2016) \\
\hline Valence & Afraid, angry, or sad faces & Survey & Witherby \& Tauber (2018) \\
\hline \multicolumn{4}{|c|}{ How Words or Images Are Presented } \\
\hline Font size & $\begin{array}{l}\text { Large: } \operatorname{dog} \\
\text { Small: } \operatorname{dog}\end{array}$ & $\begin{array}{l}\text { Survey, } \\
\text { Prestudy JOLs, } \\
\text { Learner-observer, } \\
\text { Global JOLs, } \\
\text { Ease of learning judgments }\end{array}$ & $\begin{array}{l}\text { Hu et al. (2015), Kornell et al. (2011), Mueller et al. (2014), } \\
\text { Price \& Harrison (2017), Price et al. (2016), Su et al. } \\
\text { (2018), Undorf \& Zimdahl (2018), Undorf, Zimdahl, \& } \\
\text { Bernstein (2017), Yang, Huang, \& Shanks (2018) }\end{array}$ \\
\hline Font style & $\begin{array}{l}\text { Regular: dog-spoon } \\
\text { Bold: dog-spoon } \\
\text { Italics: dog-spoon }\end{array}$ & Survey & Price et al. (2016) \\
\hline Font case & $\begin{array}{l}\text { Regular: dog-spoon } \\
\text { Alternating: DoG-SpOoN }\end{array}$ & Prestudy JOLs & Dunlosky et al. (2015) \\
\hline Font color & Printed in blue vs. green ink & Global JOLs & Mueller \& Dunlosky (2017) \\
\hline Hand writing & $\begin{array}{l}\text { Written with dominant or } \\
\text { nondominant hand }\end{array}$ & $\begin{array}{l}\text { Survey, } \\
\text { Prestudy JOLs }\end{array}$ & Susser \& Mulligan (2015), Susser et al. (2016) \\
\hline Volume & Loud vs. quiet audio & Global JOLs & Frank \& Kuhlmann (2017) \\
\hline Image quality & Intact vs. degraded image & $\begin{array}{l}\text { Survey, } \\
\text { Global JOLs }\end{array}$ & Besken (2016) \\
\hline \multicolumn{4}{|l|}{ Other Types of Cues } \\
\hline Size of mental image & $\begin{array}{l}\text { Visualize a word in large font or } \\
\text { in small font }\end{array}$ & Survey & T. Li et al. (2017) \\
\hline Study opportunities & One or two additional study trials & $\begin{array}{l}\text { Survey, } \\
\text { Both JOLs per item }\end{array}$ & Kornell \& Bjork (2009), Kornell et al. (2011) \\
\hline Retention interval & $10 \mathrm{~min}, 1$ day, or 1 week & Survey & Koriat et al. (2004) \\
\hline Truthfulness & $\begin{array}{l}\text { Generate a truthful response or a } \\
\text { plausible lie }\end{array}$ & Survey & Besken (2018) \\
\hline
\end{tabular}

in research to earn extra credit in upper-level psychology classes. Participants received course credit and were randomly assigned to making judgments for a younger adult $\left(n=33, M_{\text {age }}=19.8\right.$ years, $S E=0.4)$ or for an older adult $\left(n=31, M_{\text {age }}=20.3\right.$ years, $S E=1.2$ ). The sample was predominately female (i.e., $72 \% ; 46$ women and 18 men), Caucasian (i.e., 78\%; 50 Caucasian, 6 African American, 6 Asian, 1 Caucasian and Asian, and 1 no response), and not Hispanic (i.e., 91\%; 58 not Hispanic, 3 Hispanic, and 3 no responses). The judgment groups did not differ in terms of age $(t<1)$, race, $\chi^{2}(5, N=64)=2.96, p=$ .71 , or ethnicity, $\chi^{2}(2, N=64)=0.67, p=.71$.

Materials and procedure A 28-item word list that included 14 neutral words (e.g., cork, gender) and 14 negative words (e.g., fever, poison) was used (taken from Tauber \& Dunlosky, 2012; Zimmerman \& Kelley, 2010). Word frequencies did not differ for neutral and negative words, $t<1$.

Participants were told that they would be studying words presented one-at-a-time and that their task was to learn each for a future test. They were also informed that words would be presented for $5 \mathrm{~s}$ and that they would study 28 total words. The participants in the younger adult judgment group were then given the following instructions:

Immediately after studying each word you will enter the probability that an average younger adult (roughly 1821 years old) would be able to recall the word on a future 
test. You will type your response (from 0-100) and then press enter. Enter 0 if you are sure that an average younger adult would not recall the word. Enter 100 if you are absolutely certain that an average younger adult would recall the word. You may use any whole numbers between 0-100 for your predictions.

The participants in the older adult judgment group were given nearly identical instructions, except an "average older adult (roughly 65+ years old)" was specified.

The word list was randomized anew for each participant, and each word was presented for $5 \mathrm{~s}$. Immediately following study, participants made a JOL. The participants in the younger adult judgment group were given the prompt, "How likely would an average younger adult (roughly 18-21 years old) be to later remember the word you just studied?" The participants in the older adult judgment group were given a nearly identical prompt, except that an "average older adult (roughly 65+ years old)" was provided. A 0.25 -s interstimulus interval was used between trials. Participants completed a free-recall test on which they typed each word that they remembered. Specifically, participants typed a recalled word into a word field and hit Enter. The word then appeared in a "recall list" so that participants could keep track of their responses. This procedure continued until participants had typed all the words they could recall (for a similar free-recall procedure, see Tauber, Dunlosky, Urry, \& Optiz, 2016).

Finally, each participant made two retrospective-global judgments, one for negative words and one for neutral words. The order of the retrospective-global judgments was counterbalanced. The participants in the younger adult judgment group were given the prompts, "14 of the words you studied were emotionally negative [or neutral]. How many negative words [neutral words] do you think an average younger adult (18-21 years old) would be able to correctly remember?" and entered a value from 0 to 14 . The participants in the older adult judgment group were given nearly identical prompts, except that "average older adult (65+ years old)" was specified. For all experiments, the JOLs, free-recall tests, and retrospective-global judgments were all self-paced.

\section{Results}

Our primary interest was in participants' JOLs, so analyses of them are presented first, followed by analyses of recall performance and retrospective-global judgments.

As is evident from Fig. 1 (left panel), JOL magnitudes did not differ between participants who made JOLs for a younger adult and participants who made JOLs for an older adult. By contrast, an emotional salience effect was apparent on participants' JOLs. These observations were supported by a 2 (judgment group: younger adult vs. older adult) $\times 2$ (word type: negative vs. neutral) mixed-factor analysis of variance
(ANOVA). Specifically, JOLs were significantly higher for negative than for neutral words, $F(1,62)=12.89, p=.001$, $\eta_{\mathrm{p}}{ }^{2}=.17$. JOLs did not significantly differ by judgment group, and judgment group did not significantly interact with word type, $F \mathrm{~s}<1$.

Concerning scoring of recall, for all reported experiments, minor spelling errors that did not change the meaning of a word (e.g., a typing error or pluralizing a word) were counted as correct. The percentages of words correctly recalled were calculated per participant and separately for each word type. Recall did not differ significantly between the group who made judgments for a younger adult $(M=28.79 \%, S E=2.25)$ and the group who made judgments for an older adult $(M=33.87 \%, S E$ $=2.32), F(1,62)=2.47, p=.12, \eta_{\mathrm{p}}{ }^{2}=.004$. Participants recalled significantly more negative words $(M=36.41 \%, S E$ $=2.04)$ than neutral words $(M=26.25 \%, S E=1.78), F(1,62)=$ $24.70, p<.001, \eta_{\mathrm{p}}{ }^{2}=.29$. Judgment group did not interact with word type, $F(1,62)=3.22, p=.08, \eta_{\mathrm{p}}{ }^{2}=.05$.

In Experiment 1 (and all subsequent experiments), participants' retrospective-global judgments were transformed to percentages by dividing each judgment by the number of words studied (separately for each item type when item type was manipulated) and multiplying by 100 . The mean values are presented in Table 2. Retrospective-global judgments were not influenced by whether participants made them for a younger adult or an older adult, $F(1,62)=1.10, p=.30, \eta_{\mathrm{p}}{ }^{2}=.02$. However, an emotional salience effect was apparent on retrospective-global judgments. Specifically, a 2 (judgment group) $\times 2$ (word type) mixed-factor ANOVA revealed that retrospective-global judgments were significantly higher for negative than for neutral words, $F(1,62)=21.50, p<.001, \eta_{\mathrm{p}}{ }^{2}$ $=.26$. Judgment group did not significantly interact with word type, $F(1,62)=2.34, p=.13, \eta_{\mathrm{p}}{ }^{2}=.04$.

\section{Discussion}

In Experiment 1, participants' JOLs were significantly higher for emotional than for neutral words (cf. Hourihan \& Bursey, 2015; Nomi, Rhodes, \& Cleary, 2013; Tauber \& Dunlosky, 2012; Tauber et al., 2016; Witherby \& Tauber, 2018; Zimmerman \& Kelley, 2010), which establishes that the present method was sensitive for demonstrating a cue effect on JOLs. By contrast, participants' JOLs were not statistically different when made for an average younger adult than for an average older adult. Similar to JOLs, retrospective-global judgments were affected by valence and not by whether participants made judgments for an average younger or an average older adult.

These outcomes suggest that participants' beliefs about memory decline with aging are unrelated to their item-byitem JOLs and retrospective-global judgments. However, in Experiment 1, judgment group was manipulated between-participants. A between-participants manipulation was chosen 




Fig. 1 Mean judgments of learning for each judgment group and word type in Experiment 1 (left panel) and Experiment 2 (right panel). Error bars represent within-participant standard errors (Loftus \& Masson,

1994), which were calculated separately for each judgment group for Experiment 1. Standard errors were calculated within-participants for Experiment 2

because participants in both groups could use their experiences and beliefs about their memory in comparison with either an average younger adult or an average older adult. Even so, JOL theory suggests that judgments are inferential and based on the cues available during learning (e.g., Koriat, 1997), and in the present case, all levels of the cue were not being judged. Thus, a between-participants manipulation of judgment group may have constrained the impact of beliefs on both metacognitive judgments.

Consider the evidence from Koriat et al. (2004). Their participants studied related and unrelated word pairs, made a JOL for each, and received a cued-recall test. Some participants took the test immediately, others took it one day later, and a final group of participants took it one week later. JOLs were

Table 2 Retrospective-global judgments from Experiments 1-7

\begin{tabular}{|c|c|c|}
\hline & $\begin{array}{l}\text { Retrospective-Global Judgment } \\
\text { for a Younger Adult }\end{array}$ & $\begin{array}{l}\text { Retrospective-Global Judgment } \\
\text { for an Older Adult }\end{array}$ \\
\hline \multicolumn{3}{|l|}{ Experiment 1} \\
\hline Negative words & $65.4(2.0)$ & $56.7(1.8)$ \\
\hline Neutral words & $48.9(2.0)$ & $48.4(1.8)$ \\
\hline \multicolumn{3}{|l|}{ Experiment 2} \\
\hline Negative words & $61.1(2.6)$ & $51.2(3.0)^{* * *}$ \\
\hline Neutral words & $51.5(2.3)$ & $48.7(2.8)$ \\
\hline Experiment 3 & $40.8(1.4)$ & $32.5(1.4)^{* *}$ \\
\hline Experiment 4 & $45.3(1.5)$ & $38.0(1.5)^{*}$ \\
\hline \multicolumn{3}{|l|}{ Experiment 5} \\
\hline Negative words & $64.5(3.1)$ & $56.3(3.5)^{* *}$ \\
\hline Neutral words & $43.8(3.1)$ & $45.2(3.1)$ \\
\hline \multicolumn{3}{|l|}{ Experiment 6} \\
\hline Questionnaire first & $42.7(2.0)$ & $34.4(2.1)^{* * *}$ \\
\hline Questionnaire last & $46.6(2.3)$ & $39.9(2.4)^{*}$ \\
\hline Experiment 7 & $42.2(0.9)$ & $40.0(0.9)$ \\
\hline
\end{tabular}

Retrospective-global judgments are provided as mean percentages. Standard errors are provided in parentheses, which were calculated within-participant (Loftus \& Masson, 1994), and separately for each judgment group for Experiment 1and each questionnaire group in Experiment 6. Standard errors were calculated within-participant for all other experiments. * Mean retrospective-global judgments were significantly different for an older adult than for younger adult, $p<.05 .{ }^{* * *}$ Mean retrospective-global judgments were significantly different for older adult than for younger adult, $p<.01$. ${ }^{* * *}$ Mean retrospective-global judgments were significantly different for older adult than for younger adult, $p<.001$. 
substantially higher for the related than for the unrelated pairs, but they did not differ on the basis of retention interval. Importantly, in a follow-up experiment, the researchers manipulated retention interval within each participant, so that all participant made JOLs predicting recall in $10 \mathrm{~min}$, in one day, and in one week. This time, JOLs significantly decreased as retention interval increased. Thus, participants' JOLs became sensitive to retention interval when it was manipulated withinparticipants, as compared to when it was manipulated between-participants (see also Carroll \& Nelson, 1993). As such, it is possible that participants' JOLs (and retrospectiveglobal judgments) would become sensitive to judgment group when they were required to make judgments for both younger adults and older adults.

\section{Experiment 2}

To address this issue, a within-participant design was used in Experiment 2.

\section{Method}

Design and participants A 2 (judgment group: younger adult vs. older adult) $\times 2$ (word type: negative vs. neutral) withinparticipant design was used. Forty-three undergraduate students $\left(M_{\text {age }}=20.6\right.$ years, $\left.S E=0.47\right)$ were recruited from the department of psychological sciences subject pool at Kent State University and received course credit. The sample was predominately female (i.e., 65\%; 28 women and 15 men), Caucasian (i.e., 65\%; 28 Caucasian, 8 African American, 5 Asian, and 2 no responses), and not Hispanic (i.e., 91\%; 39 not Hispanic, 2 Hispanic, and 2 no responses).

Materials and procedure The materials were identical to those of Experiment 1, and the procedure was nearly identical. Participants made one JOL for each word (as in Exp. 1); however, all participants made two types of JOLs. For half of the words (i.e., for 14), participants made a JOL for an average younger adult (roughly 18-21 years old), and for the other half of the words, participants made a JOL for an average older adult (roughly $65+$ years old). JOL type was randomly ordered anew per participant. Additionally, participants made four retrospective-global judgments, the order of which was counterbalanced. Two retrospective-global judgments were made for an average younger adult (roughly 18-21 years old), one for neutral words and one for negative words. Two retrospective-global judgments were also made for an average older adult (roughly 65+ years old), one for neutral words and one for negative words. The prompts for the retrospectiveglobal judgments were identical to those in Experiment 1. All other aspects of the procedure were identical to those of Experiment 1.

\section{Results}

As is evident from Fig. 1 (right panel), participants' JOLs were significantly lower for an older than for a younger adult, $F(1,42)=6.19, p=.017, \eta_{\mathrm{p}}{ }^{2}=.13$, and their JOLs were also higher for negative than for neutral words, $F(1,42)=8.24, p=$ $.006, \eta_{\mathrm{p}}{ }^{2}=.16$. Judgment group did not significantly interact with word type, $F<1$.

Recall performance was significantly higher for negative $(M=34.2 \%, S E=1.20)$ than for neutral $(M=27.9 \%, S E=$ 2.08 ) words, $F(1,42)=6.40, p=.015, \eta_{\mathrm{p}}^{2}=.13$. Recall performance did not differ by judgment group (judge for older adult, $M=32.1, S E=1.8$; judge for younger adult, $M=30.1$, $S E=2.1 ; F<1$ ), and judgment group did not interact with word type, $F(1,42)=2.26, p=.14, \eta_{\mathrm{p}}{ }^{2}=.05$.

As is evident from Table 2, retrospective-global judgments were significantly lower for an older than for a younger adult, $F(1,42)=8.33, p=.006, \eta_{\mathrm{p}}{ }^{2}=.17$. They were also significantly lower for neutral than for negative words, $F(1,42)=$ $5.04, p=.03, \eta_{\mathrm{p}}{ }^{2}=.11$. Judgment group did not significantly interact with word type, $F(1,42)=3.51, p=.07, \eta_{\mathrm{p}}{ }^{2}=.08$. Even so, because the interaction approached significance, we also provide simple-effects tests for interested readers (see Table 2). For negative words, retrospective-global judgments were significantly lower for an older than for a younger adult, $t(42)=3.2, p=.003, d=0.49$, but for neutral words, this effect was not significant, $t(42)=1.1, p=.30$.

\section{Discussion}

In Experiment 2, an emotional salience effect was again evident on participants' JOLs and retrospective-global judgments. More important, participants' judgments were sensitive to judgment group. JOLs were significantly lower when made for an average older adult than when made for a younger adult, as were retrospective-global judgments. Even so, the difference between JOLs was small (i.e., approximately $71.2 \%$ for a younger adult vs. $68.6 \%$ for an older adult, a difference of $2.6 \%$ ) when compared to participants' beliefs of the impact of aging on memory (i.e., global estimate of $58.1 \%$ for a younger adult vs. $45.0 \%$ for an older adult, a difference of $13.1 \%$; see the introduction). One possibility is that valence (i.e., negative vs. neutral words) largely overshadowed the aging factor (albeit a small age effect was evident for negative words in Exp. 2).

\section{Experiment 3}

If valence did overshadow the possible effect of the age group being judged, eliminating the valence manipulation would allow participants to more carefully consider their beliefs about memory decline with age, and a more pronounced 
difference would be apparent on JOLs for a younger adult relative to an older adult. Evaluating this prediction was the primary goal of Experiment 3.

\section{Method}

Design and participants Judgment group (younger vs. older adult) was manipulated within-participant. Thirty-two undergraduate students ( $M_{\mathrm{age}}=20.3$ years, $S E=0.50$ ) were recruited from the department of psychological sciences subject pool at Kent State University and received course credit. The sample was predominately female (i.e., 75\%; 24 women and 8 men), Caucasian (i.e., 69\%; 22 Caucasian, 7 African American, 2 Asian, and 1 Caucasian and African American), and not Hispanic (i.e., 97\%; 31 not Hispanic and 1 Hispanic).

Materials and procedure In Experiment 3, the negative words from Experiments 1 and 2 were removed from the study list, and 14 neutral words replaced them (taken from Tauber \& Dunlosky, 2012; Zimmerman \& Kelley, 2010). Thus, participants studied a 28 -item word list of neutral words. The procedure was identical to that of Experiment 2. Specifically, participants made two JOLs. For half of the words, participants made a JOL for an average younger adult (roughly 18-21 years old), and for the other half, participants made a JOL for an average older adult (roughly $65+$ years old). Participants made two retrospectiveglobal judgments, the order of which was counterbalanced. One retrospective-global judgment was made for an average younger adult. Participants were given the prompt, "You studied and were tested on 28 words. How many words do you think an average younger adult (18-21 years old) would be able to correctly remember?," to which they entered a value from 0 to 28 . Another retrospective-global judgment was made for an average older adult. To do so, participants were given a nearly identical prompt, except that it specified an average older adult (roughly $65+$ years old). All other aspects of the procedure were identical to those of Experiment 2.

\section{Results}

As is evident from Fig. 2 (left panel), participants' JOLs did not differ significantly for a younger relative to an older adult, $t<1$. Recall also did not differ significantly on the basis of whether words were judged for a younger adult $(M=26.34 \%$, $S E=1.86)$ or for an older adult $(M=27.68 \%, S E=2.35), t<1$. Overall, participants recalled $27.0 \%(S E=1.6)$ of the word list.

Retrospective-global judgments were significantly lower for an older than for a younger adult (Table 2), $t(31)=3.0, p$ $=.005, d=0.53$.

\section{Discussion}

In Experiment 3, participants' retrospective-global judgments were sensitive to the age being judged, whereas participants' JOLs were statistically equivalent for an average younger and older adult. Experiments 1-3 converged on the conclusion that participants' JOLs are largely insensitive to whether they are made for an average younger versus an average older adult. One possibility is that during study, participants were so captured by studying a given item and making a JOL for it that they neglected their beliefs about the impact of healthy aging on memory. This may be particularly evident because the within-participant manipulations in Experiments 2 and 3 were at the level of the word list. That is, participants made one JOL for each word, for either a younger or an older adult. Perhaps beliefs about memory decline with aging would be evident on participants' JOLs when they were made for each word. Because manipulating person characteristics at the level of each word would encourage a direct contrast between an average younger adult and an average older adult for each item on the study list, participants were expected to use their beliefs about aging as a basis for their JOLs.

\section{Experiment 4}

To investigate this possibility in Experiment 4, a withinparticipant manipulation was used, but at the level of each word. On the basis of the rationale above, JOLs were expected to be lower when they were made for older than for younger adults.

\section{Method}

Design and participants Judgment group (younger adult vs. older adult) was manipulated within-participant. Thirty-two undergraduate students $\left(M_{\mathrm{age}}=20.0\right.$ years, $\left.S E=0.51\right)$ were recruited from the Department of Psychological Sciences subject pool at Kent State University and received course credit. The sample was predominately female (i.e., $81 \%$; 26 women and 6 men), Caucasian (i.e., 75\%; 24 Caucasian, 4 African American, 2 Asian, one other, and 1 no response), and not Hispanic (i.e., 91\%; 29 not Hispanic, 1 Hispanic, and 2 no responses).

Materials and procedure The materials were identical to those of Experiment 3 (i.e., a 28 -item study list of neutral words). The procedure was similar to that of Experiments 2 and 3. Specifically, all participants made two JOLs; however, instead of making one JOL for each word, participants made both JOLs for each. To do so, participants were given the prompts, "how likely would an average older adult (roughly $65+$ years old) be to later remember the word you just studied?" and 


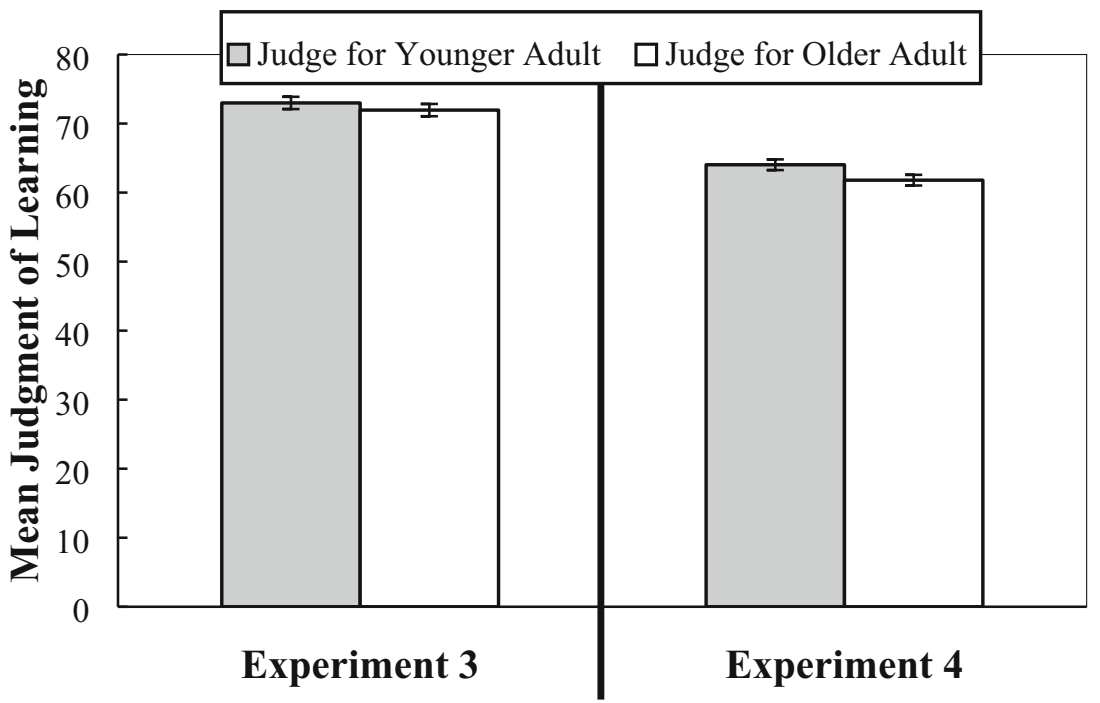

Fig. 2 Mean judgments of learning for each judgment group in Experiment 3 (left panel) and Experiment 4 (right panel). Error bars represent withinparticipant standard errors (Loftus \& Masson, 1994)

"how likely would an average younger adult (roughly 18-21 years old) be to later remember the word you studied?" on the same screen. "Older adult" and "younger adult" were underlined, bolded, and presented in a larger font than the rest of the text on the screen. Participants were instructed to read the prompts carefully to ensure that their judgments were entered into the correct fields, and they typed their JOLs into a text field next to each prompt. The presentation order of JOL prompts was counterbalanced. All other aspects of the procedure were identical to those of Experiment 3.

\section{Results}

As is evident from Fig. 2 (right panel), participants' JOLs did not significantly differ for a younger versus an older adult, $t(31)=1.5, p=.15, d=0.14$. Participants recalled $33.71 \%$ ( $S E=2.45)$ of the word list, and their retrospective-global judgments were significantly lower for an older than for a younger adult (Table 2), $t(30)=2.4, p=.023, d=0.54$.

\section{Discussion}

In Experiment 4, participants' retrospective-global judgments were again lower for an older than for a younger adult; however, participants' JOLs did not differ significantly between the judgment groups. The JOL outcome is rather surprising, given that participants made JOLs for both older and younger adults for each word on the study list - how could encouraging this direct contrast between age groups not activate people's beliefs and impact the JOLs? In Experiments 3 and 4, the valence manipulation (from Exps. 1 and 2) was dropped, so that participants studied a list of all neutral items. As we previously noted, our rationale for eliminating the valence manipulation was that it might have overshadowed the aging factor, and while plausible, the only case in which participants' JOLs were sensitive to beliefs about aging included the valence manipulation (Exp. 2). Thus, in contrast with the overshadowing hypothesis, the valence manipulation may have drawn attention to the age group being judged and enhanced the impact of judgment group on JOLs.

\section{Experiment 5}

Given that our primary goal was to increase the likelihood of observing JOL sensitivity to age group, in Experiment 5 we again included a manipulation of valence (i.e., using the materials from Exps. 1 and 2). We also had participants make two JOLs for each item (i.e., using the JOL procedure from Exp. 4), so as to encourage them to directly contrast the two age groups and to increase the likelihood that beliefs about memory decline would impact the JOLs.

\section{Method}

Design and participant A 2 (judgment group: younger adult vs. older adult) $\times 2$ (word type: negative vs. neutral) withinparticipant design was used. Forty undergraduate students $\left(M_{\text {age }}=19.9\right.$ years, $\left.S E=0.59\right)$ were recruited from the Psychology Department subject pool at Texas Christian University. The sample was predominately female (i.e., $75 \%$; 30 women and 10 men), Caucasian (i.e., 65\%; 26 Caucasian, 2 African American, 4 Asian/Pacific Islander, 1 Eastern European, one Caucasian and Asian, and 6 no response), and not Hispanic (i.e., $85 \%$; 34 not Hispanic and 6 Hispanic). The subject pool at Texas Christian University includes students enrolled in intro- 


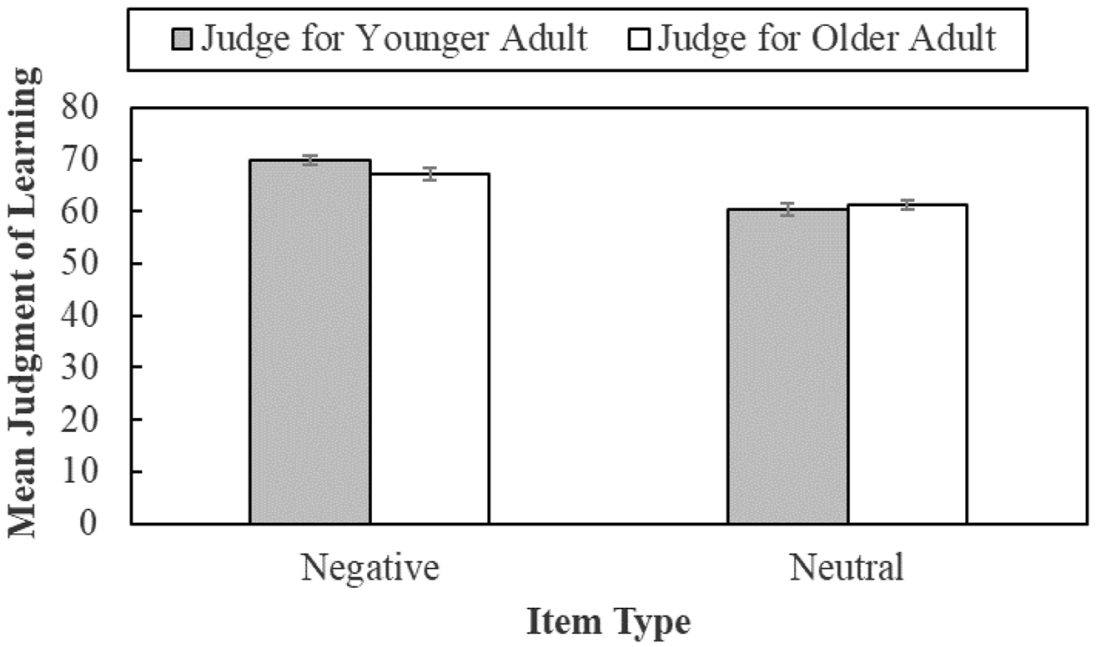

Fig. 3 Mean judgments of learning for each judgment group in Experiment 5. Error bars represent within-participant standard errors (Loftus \& Masson, 1994)

level psychology courses with the requirement to participate in research, as well as students enrolled in upper-level courses, who may participate in research to earn extra credit. All participants received course credit.

Materials and procedure The materials were identical to those of Experiments 1 and 2 (i.e., a 28-item study list of 14 neutral words and 14 negative words). The prompts for retrospective-global judgments were identical to those of Experiment 2. The procedure was identical to that of Experiment 4. Most important, all participants made two JOLs for each word, one for an average younger adult and one for an average older adult.

\section{Results}

Participants' JOLs did not differ significantly for a younger versus an older adult (Fig. 3), $F<1$, but they were significantly higher for negative than for neutral words, $F(1,39)=18.35, p<.001, \eta_{\mathrm{p}}{ }^{2}=.32$. Judgment group significantly interacted with word type, $F(1,39)=10.03$, $p=.003, \eta_{\mathrm{p}}{ }^{2}=.21$. Follow-up tests revealed that for neutral words, participants' JOLs did not differ between a younger adult and an older adult $(t<1)$. For negative words, participants' JOLs were significantly lower for an older than for a younger adult, $t(39)=2.3, p=.03$, although note that this effect size was small $(d=0.15)$.

Recall performance was significantly higher for negative words $(M=39.6 \%, S E=2.41)$ than for neutral words $(M=$ $30.5 \%, S E=1.62), t(39)=24.0, p<.001, d=0.70$.

Participants' retrospective-global judgments were significantly higher for negative than for neutral words, $F(1,39)=$ $18.32, p<.001, \eta_{\mathrm{p}}{ }^{2}=.32$ (Table 2 ), but they did not significantly differ for an older relative to a younger adult, $F(1,39)=$ $3.73, p=.06, \eta_{\mathrm{p}}{ }^{2}=.09$. However, this effect was qualified by a significant interaction between judgment group and word type, $F(1,39)=4.53, p=.04, \eta_{\mathrm{p}}{ }^{2}=.10$. For neutral words, retrospective-global judgments did not differ significantly for an older adult relative to a younger adult $(t<1)$. For negative words, retrospective-global judgments were significantly lower for an older than for a younger adult, $t(39)=2.9, p=.006, d$ $=0.39$.

\section{Discussion}

In Experiment 5, participants' retrospective-global judgments were affected more by valence than by judgment group: Retrospective-global judgments for older and younger adults were significantly higher for negative than for neutral words. For neutral words, they did not differ on the basis of judgment group, whereas for negative words, they were significantly lower for older than for younger adults.

The effects of judgment group on JOLs again were small (for negative words) to nonexistent (for neutral words). These outcomes are consistent with those reported in Experiment 2, wherein JOLs did not differ significantly on the basis of the age group being judged for neutral words, $t(42)=1.01, p=$ .32 , but they did show a small effect for negative words, $t(42)$ $=2.05, p=.05 .^{3}$ Most important, in both experiments the difference in the magnitude of JOLs for a younger relative to an older adult was small, even for negative words (i.e., for Exp. 2, the difference was 3.22\%; for Exp. 5, it was $2.71 \%$ ). Thus, the reported outcomes converge on the conclusion that beliefs about memory decline with age have little to no impact on people's JOLs. Given that the impact of valence on the

\footnotetext{
${ }^{3}$ The interaction between judgment group and valence was not significant in Experiment 2, but we included these simple-effects tests (at the request of a reviewer) in order to explore the degree to which these focal simple effects from Experiments 2 and 5 were consistent.
} 
focal outcomes pertaining to the judgment group were minor, the valence manipulation was not included in the remaining experiments.

\section{Experiment 6}

In Experiment 6, we considered another account of why the age being judged has a minimal impact on participants' JOLs: It is possible that beliefs about memory decline with age need to be explicitly triggered prior to making JOLs. That is, if participants were probed for their beliefs about the impact of aging on memory, this would require them to activate their beliefs about aging in working memory, which would be expected to increase the likelihood that the aging manipulation would influence subsequent JOLs. We explored this possibility in Experiment 6 by having participants complete the belief questionnaire that was described in the introduction. Some participants completed the questionnaire prior to study, and others completed it after taking the final test. If the use of the aging variable in making JOLs is contingent on initially having participants retrieve their beliefs about aging, then JOLs would be sensitive to the aging manipulation for participants who completed the questionnaire before making JOLs, but not for those who completed the questionnaire after making them.

\section{Method}

Design and participants A 2 (judgment condition: younger adult vs. older adult) $\times 2$ (questionnaire order: first, last) mixed-participant design was used, with judgment condition manipulated within-participants. Eighty-five undergraduate students were recruited from the Psychology Department subject pool at Texas Christian University, received course credit, and were randomly assigned to complete the belief survey either first $\left(n=43 ; M_{\text {age }}=19.5\right.$ years, $\left.S E=0.25\right)$ or last $(n=$ $42 ; M_{\text {age }}=19.4$ years, $\left.S E=0.21\right)$. The sample was predominately female (i.e., 86\%; 73 women and 12 men), Caucasian (i.e., 79\%; 67 Caucasian, 6 African American, 5 Asian/Pacific Islander, and seven no response), and not Hispanic (i.e., 92\%; 78 not Hispanic and 7 Hispanic). The groups did not differ on the basis of age $(t<1)$, gender, $\chi^{2}(1, N=85)=0.002, p=.97$, ethnicity, $\chi^{2}(3, N=85)=2.97, p=.40$, or identifying as Hispanic, $\chi^{2}(1, N=85)=0.13, p=.72$.

Materials and procedure The materials were identical to those of Experiments 3 and 4 (i.e., a 28-item study list of neutral words). The procedure was nearly identical to that of Experiment 4. Specifically, all participants made two JOLs (one for an average older adult and another for an average younger adult) for each word. Most important, in Experiment 6 the participants completed a belief questionnaire, which was identical to the questionnaire reported in the introduction (see the Appendix). Participants were randomly assigned to complete the questionnaire either first (i.e., prior to the study and JOL phases) or last (i.e., after the retrospective-global judgments) (cf. Undorf \& Zimdahl, 2019, Exp. 3). All other aspects of the procedure were identical to those of Experiment 4.

\section{Results}

To establish whether the participants in Experiment 6 believed that memory declines with age, responses to the questionnaire are reported first. Most participants (84.7\%; 72 participants) responded "yes," indicating that people's ability to learn new information declines as they become age 65 or older. Responses did not differ significantly between those who completed the questionnaire before study (88.4\%; 38 participants) versus for those who completed the questionnaire after study $(81.0 \% ; 34$ participants), $\chi^{2}(1, N=85)=0.90, p=.34$. Furthermore, participants' estimates in response to the hypothetical experiment were significantly lower for an older adult $(M=40.88 \%, S E=$ $1.7)$ than for a younger adult $(M=52.20 \%, S E=2.0), F(1$, $83)=37.11, p<.001, \eta_{\mathrm{p}}{ }^{2}=.31$. Estimates did not significantly differ on the basis of questionnaire order, and questionnaire order did not interact with judgment condition, $F \mathrm{~s}$ $<1$. Thus, participants' responses on the belief questionnaire replicated those reported in the introduction and established that the participants in Experiment 6 believed that aging negatively affects memory.

Concerning JOLs (Fig. 4), the magnitude of JOLs was not influenced by questionnaire order, $F<1$, but it was significantly lower when made for an older adult $(M=63.95, S E=$ 2.17) than for a younger adult $(M=68.44, S E=1.99), F(1,83)$ $=17.21, p<.001, \eta_{\mathrm{p}}{ }^{2}=.17$. Judgment condition and questionnaire order did not interact significantly, $F<1$.

Participants recalled $30.76 \%(S E=1.41)$ of the word list, which did not differ on the basis of whether participants completed the survey first $(M=29.82 \%, S E=2.06)$ or last $(M=$ $31.72 \%, S E=1.96), t<1$.

Retrospective-global judgments are reported in Table 2, and due to a programming error, they were not recorded for two participants. Retrospective-global judgments were significantly lower for an older than for a younger adult, $F(1,81)=$ $18.20, p<.001, \eta_{\mathrm{p}}{ }^{2}=.18$. Retrospective-global judgments did not differ on the basis of questionnaire order, $F(1,81)=3.40$, $p=.07, \eta_{\mathrm{p}}{ }^{2}=.04$, and judgment group did not interact significantly with questionnaire order, $F<1$. Retrospective-global judgments were significantly lower for an older than for a younger adult, for both the questionnaire-first group, $t(42)=$ $4.31, p<.001, d=0.62$, and the questionnaire-last group, $t(39)$ $=2.23, p=.03, d=0.45$. 


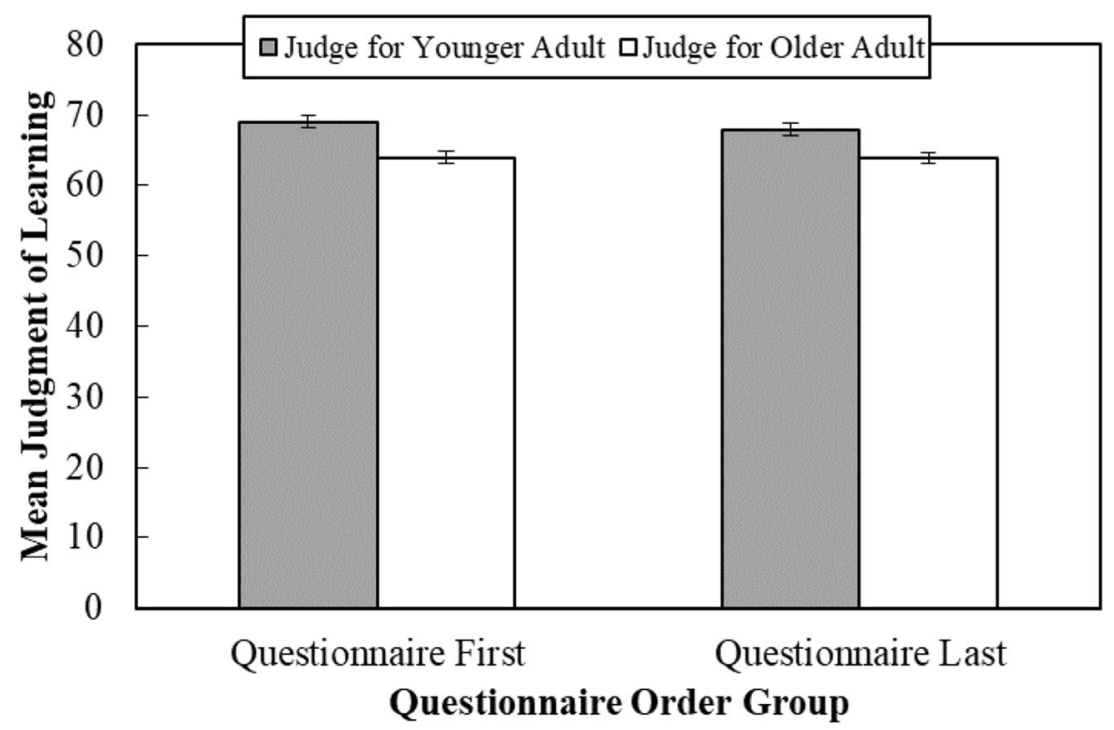

Fig. 4 Mean judgments of learning for each judgment group in Experiment 6. Error bars represent within-participant standard errors (Loftus \& Masson, 1994), which were calculated separately for each questionnaire order group

\section{Discussion}

In Experiment 6, participants' JOLs were significantly lower for an older than for a younger adult, which was true of both questionnaire order groups. Thus, it is unlikely that explicitly triggering participants' beliefs about healthy aging prior to making JOLs is necessary in order to increase the sensitivity of JOLs to the judged age group. As important, the difference in JOL magnitude for an older relative to a younger adult was small (questionnaire first, $M_{\text {diff }}=5.02$; questionnaire last, $M_{\text {diff }}$ $=3.95$ ). This difference is in direct contrast with the larger difference in estimates provided on the questionnaires $\left(M_{\text {diff }}\right.$ $=11.34$ ).

\section{Experiment 7}

We explored one more reason why participants' JOLs would appear to be largely unrelated to beliefs about the impact of aging on memory. Namely, the lack of JOL sensitivity might be attributable to poor statistical reasoning when making judgments for someone else. When considering a single word, participants might believe that anyone has about the same chance of remembering it, and not consider that on average (across all items), aging in adulthood could influence the likelihood of remembering a single item. That is, when making a JOL for any given item for an older or younger adult, participants might neglect the fact that the individual word is embedded within a larger list of to-be-remembered words. By contrast, when judgments require considering performance across an entire list, age group might be expected to have a larger impact. This possibility is consistent with the evidence that the estimates from questionnaires (and often the retrospective-global judgments) demonstrate larger effects of the age group being judged than do the item-by-item JOLs (which demonstrate little to no effect).

Direct evidence for the contribution of poor statistical reasoning would involve having participants make item-by-item JOLs during study (as in the prior studies) and make global predictions during study, as well. If poor statistical reasoning partly contributed to the meager effects of age group on itemby-item JOLs, then (a) JOLs would be largely unrelated to the manipulation of age group (as in prior studies), whereas (b) embedded global judgments would be more influenced by it. An alternative, however, is that when studying the list of words, participants are more influenced by their experiences during study than by their beliefs about aging. Such experiences would be minimized for questionnaire data (in which no items are studied) or retrospective judgments (which are made well after study). If the experience of making judgments concurrently during the study phase diminishes the impact of age group, then JOLs and global predictions made during study would be equally insensitive to this manipulation.

To test these alternatives in Experiment 7, participants made a global judgment for an older adult and for a younger adult halfway through the study list. Thus, participants studied and made two JOLs for 14 words, after which they judged how many of them an older and a younger adult would remember. Participants then studied and made two JOLs for the remaining 14 words, completed a memory test, and made retrospective-global judgments.

\section{Method}

Design and participants Judgment group (younger adult vs. older adult) was manipulated within-participant. Forty 
undergraduate students $\left(M_{\text {age }}=18.8\right.$ years, $\left.S E=0.23\right)$ were recruited from the Psychology Department subject pool at Texas Christian University and received course credit. The sample was predominately female (i.e., $80 \%$; 32 women and 8 men), Caucasian (i.e., 90\%; 36 Caucasian, 1 Asian/Pacific Islander, and 3 no response), and not Hispanic (i.e., 93\%; 37 not Hispanic and 3 Hispanic).

Materials and procedure The materials were identical to those of Experiments 3, 4, and 6 (i.e., a 28-item study list of neutral words). The procedure was nearly identical to that of Experiment 4. Specifically, all participants made two JOLs (one for an average older adult and another for an average younger adult) for each word. Most important, in Experiment 7, after participants had studied and made JOLs for half (i.e., 14) of the items, they made two midlist global judgments. To do so, participants were given the prompt, "So far, you studied 14 words. How many of these words do you think an average young adult (roughly 18-21 years old) would be able to remember?," to which they entered a value from 0 to 14 in a field. The older adult prompt was identical, except that it referenced an average older adult (roughly 65+ years old). The order of midlist global judgments was counterbalanced. The rest of the procedure was identical to that of Experiment 4.

\section{Results}

Because it is the novel addition to Experiment 7, we first provide analyses of participants' midlist global judgments. These global judgments were transformed to percentages by dividing each by 14 and multiplying by 100 . Midlist global judgments were significantly lower for an older adult $(M=$ $59.8, S E=2.7)$ than for a younger adult, $M=65.9, S E=2.7$, $t(39)=2.14, p=.04, d=0.36$.

Participants' JOLs did not differ significantly for a younger adult $(M=66.6, S D=2.5)$ relative to an older adult $(M=66.2, S E=2.4), t<1$. We explored participants' JOLs further by averaging them separately for those made prior to the midlist global judgments and those made after the midlist global judgments. As is evident from Fig. 5, participants' JOLs did not differ significantly for a younger adult relative to an older adult, regardless of whether they were made before or after the midlist global judgments. These observations were supported by a 2 (judgment condition: younger adult vs. older adult) $\times 2$ (location in list: prior to vs. after midlist global judgments) repeated measures ANOVA. The magnitude of JOLs did not differ for a younger versus an older adult, $F<1$. JOLs did not differ significantly on the basis of location in the list, $F<1$. Finally, judgment condition and location in the list did not interact significantly, $F(1,39)=1.32, p=.26, \eta_{\mathrm{p}}{ }^{2}=.03$.
Regarding recall performance, participants recalled 32.5\% $(S E=1.98)$ of the words from the list.

Participants' retrospective-global judgments did not differ significantly for an older versus a younger adult, $t(39)=1.22$, $p=.23$ (Table 2).

\section{Continuously cumulating meta-analyses}

Taken together, Experiments 1-7 reveal that participants' JOLs show little-to-no relationship with beliefs about memory decline with age. Nevertheless, some outcomes were significant, and trends were often in the expected direction, suggesting that combining the outcomes across experiments might yield a better estimate of the overall effect size. Accordingly, we conducted a continuously cumulating meta-analysis (CCMA) on participants' JOLs (Braver, Thoemmes, \& Rosenthal, 2014). This analysis allowed us to aggregate data across multiple experiments to calculate a pooled effect size. The average JOLs made for a younger and an older adult were included from Experiments 1-7. The CCMA analysis revealed that JOLs did not differ significantly when made for a younger adult relative to an older adult (pooled $d=0.12$, $95 \% \mathrm{CI}=-0.28,0.04$; see Table 3 , top panel). This lack of an effect is inconsistent with the predictions from both the cueutilization framework and analytic-processing theory.

Experiments 1-7 showed that participants' retrospectiveglobal judgments were generally sensitive to participants' beliefs about memory decline with age. Although retrospectiveglobal judgments were numerically lower for an older than for a younger adult in most comparisons, these trends were not always significant (and in one case, the trend was in the opposite direction). Accordingly, to estimate the overall effect size (so as to compare it with the abovementioned effect size for JOLs), we conducted a CCMA analysis of the effect of the age group being judged on participants' retrospective-global judgments. As is shown in the bottom panel of Table 3, retrospective-global judgments were significantly lower for an older than for a younger adult (with a medium effect size: pooled $d=0.33,95 \% \mathrm{CI}=-0.49,-0.17)$. Note that the CCMA analysis is intended for between-participants experiments; thus, the pooled effect sizes might underestimate the population effect sizes. Even so, given that this possible limitation would hold for analyses of both kinds of judgments, it is reasonable to conclude that judgment group has a larger impact on participants' retrospective-global judgments than on their JOLs.

\section{General discussion}

People's beliefs about normal memory decline in aging had a small and often nonsignificant impact on their JOLs. 


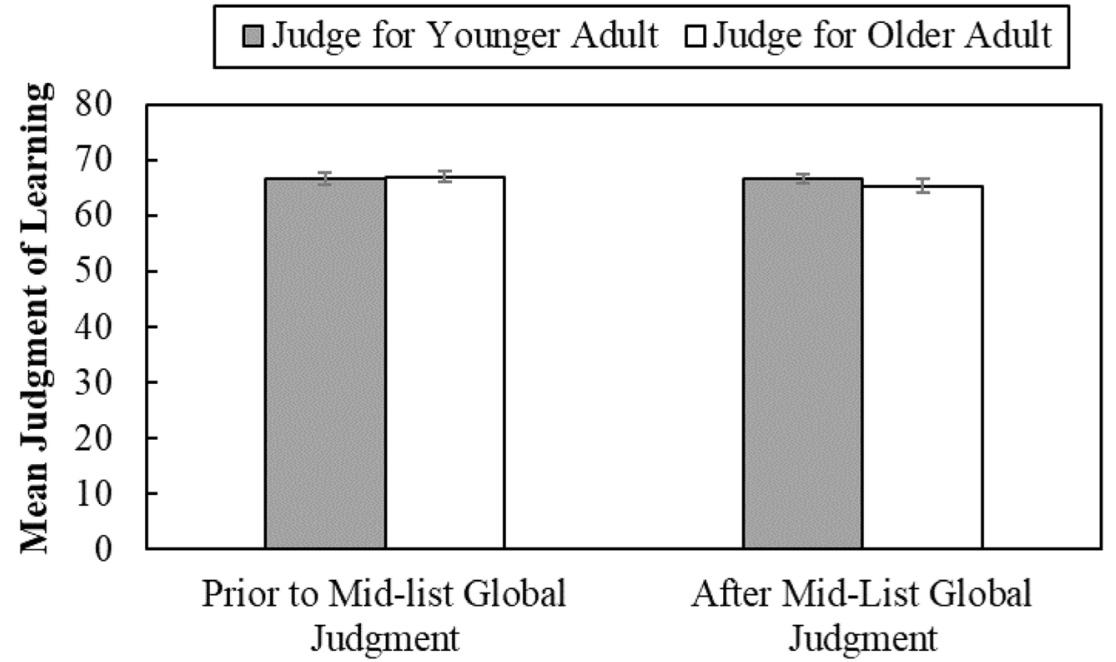

Fig. 5 Mean judgments of learning for each judgment group in Experiment 7. Error bars represent within-participant standard errors (Loftus \& Masson, 1994)

Specifically, JOLs made for an average older adult did not differ from those made for an average younger adult when judgment group (i.e., judge for an older or a younger adult)

Table 3 Continuously cumulating meta-analyses (CCMAs) for Experiments 1-7

\begin{tabular}{|c|c|c|c|c|c|c|}
\hline & Mean Diff & $S_{\text {pooled }}$ & $t$ & $p$ & Cohen's $d$ & $Z$ \\
\hline \multicolumn{7}{|c|}{$\begin{array}{l}\text { CCMA for Judgments of Learning made for Younger Adult vs. Older } \\
\text { Adult }\end{array}$} \\
\hline Experiment 1 & 0.94 & 25.00 & 0.15 & .88 & 0.04 & 0.15 \\
\hline Experiment 2 & 2.52 & 18.51 & 0.63 & .53 & 0.14 & 0.63 \\
\hline Experiment 3 & 1.04 & 14.93 & 0.28 & .78 & 0.07 & 0.28 \\
\hline Experiment 4 & 2.24 & 16.74 & 0.53 & .60 & 0.13 & 0.53 \\
\hline Experiment 5 & 0.89 & 17.88 & 0.22 & .82 & 0.05 & 0.22 \\
\hline Experiment 6 & 4.49 & 19.09 & 1.53 & .13 & 0.24 & 1.53 \\
\hline Experiment 7 & 0.39 & 15.33 & 0.11 & .91 & 0.03 & 0.11 \\
\hline CCMA results & & & & .14 & 0.12 & 1.30 \\
\hline \multicolumn{7}{|c|}{$\begin{array}{l}\text { CCMA for Retrospective-Global Judgments for Younger Adult vs. Older } \\
\text { Adult }\end{array}$} \\
\hline Experiment 1 & 4.61 & 17.60 & 1.05 & .30 & 0.26 & 1.04 \\
\hline Experiment 2 & 6.40 & 16.54 & 1.79 & .08 & 0.39 & 1.77 \\
\hline Experiment 3 & 8.37 & 15.73 & 2.13 & .04 & 0.53 & 2.08 \\
\hline Experiment 4 & 7.26 & 13.43 & 2.13 & .04 & 0.54 & 2.08 \\
\hline Experiment 5 & -3.39 & 14.59 & 1.04 & .30 & 0.23 & 1.03 \\
\hline Experiment 6 & 7.53 & 14.26 & 3.40 & .0008 & 0.53 & 3.34 \\
\hline Experiment 7 & 2.23 & 13.15 & 0.76 & .45 & .017 & 0.76 \\
\hline CCMA results & & & & $<.001$ & 0.33 & 4.57 \\
\hline
\end{tabular}

The top panel represents the effect size of the difference in the magnitude of JOLs for an older relative to a younger adult. A homogeneity test was nonsignificant, $Q(6)=1.0, p=.99, I^{2}=0.00$. The bottom panel represents the effect size of the difference in magnitude of retrospective-global judgments for an older relative to a younger adult. A homogeneity test was nonsignificant, $Q(6)=9.80, p=.13, I^{2}=38.80$. was manipulated between-participants (Exp. 1), when judgment group was manipulated within-participant at the list level (Exp. 3), or when judgment group was manipulated withinparticipants at the word level (Exps. 4, 5, and 7). In only two experiments (Exps. 2 and 6) were participants' JOLs significantly lower when made for an average older adult than when they were made for an average younger adult. Moreover, a CCMA analysis that included data from Experiments 1-7 was nonsignificant (pooled $d=0.12$ ), suggesting that this effect is small and not robust.

Contemporary theories of JOLs implicate beliefs as being critical for how people make JOLs, so the present outcomes are surprising, because people believe that aging negatively impacts learning and memory (e.g., Ryan, 1992; Ryan \& See, 1993). This belief was revealed by evidence from Lineweaver and Hertzog (1998), and converging evidence from the present research was obtained using a survey method based on samples of college students at two universities (see the introduction and Exp. 6). Furthermore, ample evidence indicates that other beliefs that people have about memory impact their JOLs (e.g., Hu et al., 2015; Jia et al., 2016; Mueller \& Dunlosky, 2017; Mueller et al., 2016; Mueller et al., 2014; Mueller et al., 2013; Susser, Jin, \& Mulligan, 2016; Witherby \& Tauber, 2017). Additional evidence of the influence of people's beliefs comes from research about memory self-efficacy, which pertains to people's beliefs about how well they can remember information (e.g., Hertzog, Dixon, \& Hultsch, 1990). Relative to younger adults, older adults typically have lower memory self-efficacy, which contributes to lower memory predictions. Thus, people's beliefs about their ability to remember information influence their predictions.

Even though people typically believe that aging negatively impacts memory, given the present outcomes, beliefs about the impact of a cue on memory are not sufficient for that cue to impact JOLs. Beliefs also do not appear to be necessary, 
given that evidence has revealed a direct - albeit small-impact of processing fluency on JOLs that cannot be attributed to beliefs (e.g., Besken, 2016; Besken \& Mulligan, 2014; Susser \& Mulligan, 2015; Undorf \& Erdfelder, 2015). This conclusion is also supported by evidence from Frank and Kuhlmann (2017), who found that most of their participants believed that they would remember more loud words than quiet words, which was also evident in their JOLs. Most important, some participants did not hold the volume belief, yet volume still had an impact on their JOLs analogous to the participants who did show such a belief. Although these outcomes do confirm the hypothesis that beliefs are not necessary, they might still have influenced these participants' JOLs. For instance, some participants who did not report the volume belief prior to the task might have formed the belief during the task. That is, after gaining experience with a few items, participants might have created the belief that volume would impact their memory and used it as a basis for their JOLs (cf. Mueller \& Dunlosky, 2017). To evaluate such possibilities, an important direction for future research will be to develop methods to measure participants' beliefs before, during, and after a task to evaluate when participants are creating them and the degree to which they influence JOLs.

\section{Explaining the (minimal) impact of beliefs about aging on JOLs}

In this section, we consider a variety of explanations that may provide answers to the following question: Why were people's JOLs largely unrelated to their beliefs about memory decline in aging? By doing so, we rule out one uninteresting possibility (that participants were not motivated to perform the JOL task) and consider some others (poor theory of mind, poor statistical reasoning, and belief intensity) to guide future research.

Lack of motivation One possibility is that participants did not understand their task and were generally not motivated to construct accurate JOLs. In the present experiments, no specific directions were given to participants about how to go about the task, and no incentives were offered to make accurate JOLs. Thus, participants might have made their JOLs somewhat randomly. The current evidence is not consistent with this possibility, however. First, one other factor (emotional valence) consistently impacted both JOLs and recall performance. Second, if participants were not motivated to make JOLs, little to no relationship would have emerged between JOLs and memory performance. To explore this possibility, we calculated JOL resolution by using a within-participant correlation between JOLs and subsequent memory performance (Nelson, 1984). As is evident from Table 4, the correlations were generally positive and significantly greater than chance. Thus, it is unlikely that participants were not motivated and simply made their JOLs at random. The correlations also exhibit patterns typically observed in the JOL resolution literature. Specifically, the overall correlations were more often significantly greater than chance when word type was manipulated (Exps. 1, 2, and 5) than when it was not (e.g., Exps. 3, 6, and 7).

If participants were generally not motivated during the task or if they had little understanding of how to make their judgments, this should apply to their retrospective-global judgments, as well. In this case, beliefs about the negative impact of aging on memory should have had a minimal (or no) impact on their retrospective-global judgments. By contrast, participants' retrospective-global judgments were typically lower for an older than for a younger adult (Table 2). Indeed, a CCMA analysis revealed that participants' beliefs about cognitive decline with age had a significant impact on retrospective-global judgments, with a pooled effect size that was moderate in magnitude (pooled $d=0.33$ ). Considering this outcome along with the above-chance resolution of JOLs, it seems unlikely that participants performed the tasks at random and with little understanding of how to make their judgments.

Theory of mind and perspective taking Another reason why participants' JOLs were unrelated to memory decline in aging may be because, to make JOLs for another person, participants must have a well-developed theory of mind. Theory of mind includes the capacity to realize that another person's mental state can be different from one's own (e.g., Flavell, 1999). To make JOLs for an older adult, we expected participants to consider experiences by a typical older adult, which might involve pretending to be someone who is age 65 or older. However, taking the perspective of another individual might be challenging. For example, Tullis and Fraundorf (2017) had participants generate cues to help them remember target words or study cue-target pairs. Most important, participants who generated cues rated the effectiveness of them for other learners, and participants who studied the word pairs made JOLs for themselves. Whereas participants' predictions of the effectiveness of cues for another learner exceeded chance, self-JOLs were much more accurate. These outcomes suggest that participants had difficulty taking the perspective of other learners. Thus, it may be that beliefs have little impact on JOLs if the cue requires considering another person's experiences, especially if those experiences diverge greatly from one's own.

Poor statistical reasoning about cues that require perspective taking Participants' JOLs may have been largely unrelated to beliefs about the impact of aging on memory due to poor statistical reasoning. From this perspective, participants may have difficulty using a belief as the basis for a JOL when doing so requires (a) taking the perspective of another person and (b) considering the likelihood of remembering a single item at a time. An error in statistical reasoning would arise if participants neglect the fact that each item is part of a larger list; in 
Table 4 JOL resolution, as measured with mean gamma correlations for Experiments 1-7

\begin{tabular}{llll}
\hline Experiment & $\begin{array}{l}\text { Judge for } \\
\text { Younger Adult }\end{array}$ & $\begin{array}{l}\text { Judge for } \\
\text { Older Adult }\end{array}$ & Overall \\
\hline Experiment 1 & $.08(.06)$ & $.29(.06)^{* * *}$ & $.18(.05)^{* * * *}$ \\
Experiment 2 & $.16(.08)^{*}$ & $.22(.07)^{* *}$ & $.19(.06)^{* *}$ \\
Experiment 3 & $.14(.09)$ & $.06(.09)$ & $.10(.06)$ \\
Experiment 4 & $.21(.06)^{* * *}$ & $.17(.06)^{* * *}$ & \\
Experiment 5 & $.18(.06)^{* *}$ & $.20(.06)^{* * *}$ & \\
Experiment 6 & $.03(.04)$ & $.12(.04)^{* * *}$ & \\
Experiment 7 & $.04(.05)$ & $.13(.05)^{* * *}$ & \\
\hline
\end{tabular}

Significantly greater than zero, ${ }^{*} p<.05 .,{ }^{* *} p<.01 .{ }^{* * * *} p \leq .001$. Overall gamma correlations were not calculated for Experiments 4, 5, 6, and 7 because participants in those experiments made two JOLs (one for a younger adult and another for an older adult) for each item. Thus, to calculate an overall gamma correlation the two JOLs would need to be averaged per item and correlated with recall performance, which would not reflect overall JOL resolution accurately.

such a case, participants might believe that everyone has the same chance of recalling any single item, and hence would not consider their belief that older adults (as compared to younger ones) would perform worse across all items. Consistent with this possibility, the item-by-item JOLs in Experiment 7 did not differ significantly for the age group being judged, whereas global judgments were significantly lower for older than for younger adults. Beyond replicating these preliminary outcomes, an important avenue for future research will be to reveal the degree to which statistical reasoning errors influence people's JOLs.

Belief intensity A final explanation for why people's JOLs were largely unrelated to beliefs about memory decline with aging is the possibility that not all beliefs are created equal. One potentially relevant dimension is the intensity or strength of the belief (cf. Frank \& Kuhlmann, 2017). According to this intensity hypothesis, strongly held beliefs are sufficient to impact JOLs, whereas weakly held beliefs are less so. We would argue that intensity (or strength) can be operationalized in two ways, which are discussed in turn in the following paragraphs.

Intensity could refer to a person's belief about the degree to which a particular factor (or cue) impacts memory. To illustrate, contrast two people, one of whom believes that an older adult would typically recall $25 \%$ of to-be-learned items and a younger adult would recall $60 \%$ of the items, and another person who believes that an older adult would recall $40 \%$ of the items and a younger adult would recall $50 \%$ of the items. In this example, even though the estimates are in the same direction, the first person holds a stronger belief about the impact of aging on memory (i.e., a 35\% difference in estimates) than does the second person (i.e., a $10 \%$ difference in estimates). According to the intensity hypothesis, this operationalization of intensity would be associated with larger effects of the aging manipulation on JOLs (cf. Frank \& Kuhlmann, 2017). To explore this possibility, we revisited data from Experiment 6. For each participant, a belief intensity score was computed by subtracting the estimates for older adults (in response to the hypothetical experiment) from the estimates for younger adults. On average, belief intensity scores were positive $(M=10.27, S E=3.05)$, because estimates tended to be lower for an older than for a younger adult. A JOL effect score was also calculated for each participant by subtracting the JOLs made for an older adult from the JOLs made for a younger adult. JOL effect scores were positive ( $M$ $=4.49, S E=1.08$ ). Of most interest, a correlational analysis of the belief intensity scores and JOL effect scores was positive and significant (Pearson $r=.32, p=.003$ ). Thus, more intense beliefs about memory decline with aging were associated with larger JOL effects. A similar relationship has also been reported in another domain. Ariel, Hines, and Hertzog (2014) measured participants' beliefs about the impact of additional study opportunities on learning and found them to be predictive of later item-by-item predictions of learning.

Another way to operationalize belief intensity is the degree to which a person is confident in his or her own belief, with less confidence in one's belief that a cue impacts memory resulting in a smaller impact on JOLs. So, even when people hold the same belief that normal aging negatively impacts memory, some might be very confident that their belief is accurate, whereas others might be less confident. The two versions of the intensity hypothesis (based on the two distinct operationalizations of strength) for why JOLs were only minimally impacted by beliefs are not mutually exclusive - both might contribute. Our data (as well as those of Ariel et al., 2014, and Frank \& Kuhlmann, 2017) provide some support for the first explanation, and an important direction for future research will be to simultaneously estimate the contributions of both kinds of belief intensity on JOLs.

\section{Concluding remarks}

Beliefs about memory decline in aging have minimal impact on participants' JOLs. This effect is striking, given that people believe that memory declines with aging in adulthood and that both the theory of JOLs and ample evidence implicate beliefs as being important for obtaining cue effects on JOLs. The belief component of all JOL theory must be updated in light of these outcomes, and the current evidence suggests that (a) people may have difficulty using beliefs as a basis for JOLs when doing so requires taking the perspective of another person, and (b) the strength of one's beliefs may play a role in moderating the relation between beliefs and JOLs. 
Author note This research was supported by a James $\mathrm{S}$. McDonnell Foundation 21st Century Science Initiative in Bridging Brain, Mind, and Behavior Collaborative Award. The materials and data for all experiments have been uploaded to the Open Science Framework and can be accessed at https://osf.io/kvg5u. The experiments were not preregistered.

\section{Appendix}

Below is the belief questionnaire completed by participants discussed in the introduction and in Experiment 6.

Do you think aging influences memory? That is, do people's ability to learn new information decline as they become 65 years or older? YES NO

In a previous experiment that we conducted, older adults (roughly 65+ years old) and younger adults (roughly 18-21 years old) were presented with a list of 28 words one after the other. Each word was presented for $5 \mathrm{sec}$ onds. The task was to study these words so they would be able to remember them for a later test. The memory test took place immediately after all of the words had been studied. On the test, older and younger adults were given unlimited time to list the words that they could remember in any order.

We would like you to estimate how many words the older adults and younger adults remembered. Your estimates can range from 0 to 28 words. An estimate of 0 words means that the older adults (or younger adults) did not remember any words, whereas an estimate of 28 words means that older adults (or younger adults) remembered all of the words.

How many words do you think the older adults remembered? (0-28)

How many words do you think the younger adults remembered? $(0-28)$

Four versions of the questionnaire were created to counterbalance question order (direct aging question first or hypothetical experiment first) and the order of age group (younger adults first or older adults first). For the students discussed in the introduction, questionnaire version did not impact either responses to the direct aging question, $\chi^{2}(6, N=43)=6.5, p=$ .37 , or estimates from the hypothetical experiment $\left(F_{\mathrm{S}}<1\right)$.

Similarly, for the participants in Experiment 6, questionnaire version did not impact either responses to the direct aging question, $\chi^{2}(3, N=85)=5.1, p=.17$ or estimates from the hypothetical experiment [younger adult estimates: $F(3,81)$ $=1.86, p=.14$; older adult estimates: $F<1]$.
Publisher's note Springer Nature remains neutral with regard to jurisdictional claims in published maps and institutional affiliations.

\section{References}

Ariel, R., Hines, J. C., \& Hertzog, C. (2014). Test framing generates a stability bias for predication of learning by causing people to discount their learning beliefs. Journal of Memory and Language, 75, 181-198. doi:https://doi.org/10.1016/j.jml.2014.06.003

Besken, M. (2016). Picture-perfect is not perfect for metamemory: Testing the perceptual fluency hypothesis with degraded images. Journal of Experimental Psychology: Learning, Memory, and Cognition, 42, 1417-1433. doi:https://doi.org/10.1037/xlm0000246

Besken, M. (2018). Generating lies produces lower memory predictions and higher memory performance than telling the truth: Evidence for a metacognitive illusion. Journal of Experimental Psychology: Learning, Memory, and Cognition, 44, 465-484.

Besken, M., \& Mulligan, N. W. (2013). Easily perceived, easily remembered? Perceptual interference produces a double dissociation between metamemory and memory performance. Memory \& Cognition, 41, 897-903.

Braver, S. L., Thoemmes, F. J., \& Rosenthal, R. (2014). Continuously cumulating meta-analysis and replicability. Perspectives on Psychological Science, 9, 333-342. doi:https://doi.org/10.1177/ 1745691614529796

Carroll, M., \& Nelson, T. O. (1993). Effect of overlearning on the feeling of knowing is more detectable in within-subject than in betweensubject designs. American Journal of Psychology, 106, 227-235.

Carstensen, L. L. (1993). Motivation for social contact across the life span: A theory of socioemotional selectivity. In J. Jacobs (Ed.), Nebraska symposium on motivation: Vol. 40. Developmental perspectives on motivation (pp. 209-254). Lincoln, NE: University of Nebraska Press.

Carstensen, L. L. (1995). Evidence for a life-span theory of socioemotional selectivity. Current Directions in Psychological Science, 4, 151-156.

Dunlosky, J., \& Hertzog, C. (2000). Updating knowledge about encoding strategies: A componential analysis of learning about strategy effectiveness from task experience. Psychology and Aging, 15, 462-474. doi:https://doi.org/10.1037/0882-7974.15.3.462

Dunlosky, J., Mueller, M. L., \& Tauber, S. K. (2015). The contribution of processing fluency (and beliefs) to people's judgments of learning. In D. S. Lindsay, A. P. Yonelinas, \& H. L. Roediger III. (Eds.), Remembering: Attributions, processes, and control in human memory: Essays in honor of Larry Jacoby (pp. 46-64). New York, NY, US: Psychology Press.

Flavell, J. H. (1999). Cognitive development: Children's knowledge about the mind. Annual Review of Psychology, 50, 21-45.

Frank, D. J., \& Kuhlmann, B. G. (2017). More than just beliefs: Experience and beliefs jointly contribute to volume effects on metacognitive judgments. Journal of Experimental Psychology: Learning, Memory, and Cognition, 43, 680-693.

Hertzog, C., Dixon, R. A., \& Hultsch, D. F. (1990). Relationships between metamemory, memory predictions, and memory task performance in adults. Psychology and Aging, 5, 215-227.

Hertzog, C., \& Hultsch, D. F. (2000). Metacognition in adulthood and old age. In F. I. M. Craik \& T. A. Salthouse (Eds.), The handbook of aging and cognition (pp. 417-466). Mahwah, NJ: Erlbaum.

Hourihan, K. L., \& Bursey, E. (2015). A misleading feeling of happiness: Metamemory for positive emotional and neutral pictures. Memory, 25, 35-43. doi:https://doi.org/10.1080/09658211.2015.1122809

Hoyer, W. J., \& Verhaeghen, P. (2006). Memory aging. In J. E. Birren \& K. W. Schaie (Eds.), Handbook of the psychology of aging (Vol. 6, pp. 209-232). London, UK: Academic Press. 
Hu, X., Li, T., Zheng, J., Su, N., Liu, Z., \& Luo, L. (2015). How much do metamemory beliefs contribute to the font-size effect in judgments of learning? PLoS ONE, 10, e142351:1-11. doi:https://doi.org/10. 1371/journal.pone.0142351

Jia, X., Li, P., Li, X., Zhang, Y., Cao, W., Cao, L., \& Li, W. (2016). The effect of word frequency on judgments of learning: Contributions of beliefs and processing fluency. Frontiers in Psychology, 6, 1995:110. doi:https://doi.org/10.3389/fpsyg.2015.01995

Koriat, A. (1997). Monitoring one's own knowledge during study: A cue utilization approach to judgments of learning. Journal of Experimental Psychology: General, 126, 349-370. doi:https://doi. org/10.1037/0096-3445.126.4.349

Koriat, A., Bjork, R. A., Sheffer, L., \& Bar, S. K. (2004). Predicting one's own forgetting: The role of experience-based and theory based processes. Journal of Experimental Psychology: General, 133, 643656. doi:https://doi.org/10.1037/0096-3445.133.4.643

Kornell, N., \& Bjork, R. A. (2009). A stability bias in human memory: Overestimating remembering and underestimating learning. Journal of Experimental Psychology: General, 138, 449-468. doi:https:// doi.org/10.1037/a0017350

Kornell, N., Rhodes, M. G., Castel, A. D., \& Tauber, S. K. (2011). The ease-of-processing heuristic and the stability bias: Dissociating memory, memory beliefs, and memory judgments. Psychological Science, 2, 787-794.doi:https://doi.org/10.1177/ 0956797611407929

Li, P., Jia, X., Li, X., \& Li, W. (2016). The effect of animacy on metamemory. Memory \& Cognition, 44, 696-705. doi:https://doi. org/10.3758/s13421-016-0598-7

Li, T., Hu, X., Zheng, J., Su, N., Liu, Z., \& Luo, L. (2017). The influence of visual mental imagery size on metamemory accuracy in judgment of learning. Memory, 25, 244-253.

Lineweaver, T. T., \& Hertzog, C. (1998). Adults' efficacy and control beliefs regarding memory and aging: Separating general from personal beliefs. Aging, Neuropsychology, and Cognition, 5, 264-296.

Loftus, G. R., \& Masson, M. E. J. (1994). Using confidence intervals in within-subject designs. Psychonomic Bulletin \& Review, 1, 476490. doi:https://doi.org/10.3758/BF03210951

Mather, M., \& Carstensen, L. L. (2005). Aging and motivated cognition: The positivity effect in attention and memory. Trends in Cognitive Sciences, 9, 496-502.

Mueller, M. L., \& Dunlosky, J. (2017). How beliefs can impact judgments of learning: Evaluating analytic processing theory with beliefs about fluency. Journal of Memory and Language, 93, 245-258.

Mueller, M. L., Dunlosky, J., \& Tauber, S. K. (2016). The effect of identical word pairs on people's metamemory judgments: What are the contributions of processing fluency and beliefs about memory? Quarterly Journal of Experimental Psychology, 69, 781-799. doi:https://doi.org/10.1080/17470218.2015.1058404

Mueller, M. L., Dunlosky, J., Tauber, S. K., \& Rhodes, M. G. (2014). The font-size effect on judgments of learning: Does it exemplify fluency effects or reflect people's beliefs about memory? Journal of Memory and Language, 70, 1-12. doi:https://doi.org/10.1016/j.jml.2013.09. 007

Mueller, M. L., Tauber, S. K., \& Dunlosky, J. (2013). Contributions of beliefs and processing fluency to the effect of relatedness on judgments of learning. Psychonomic Bulletin \& Review, 20, 378-384.

Nelson, T. O. (1984). A comparison of current measures of the accuracy of feeling-of-knowing predictions. Psychological Bulletin, 95, 109133. doi:https://doi.org/10.1037/0033-2909.95.1.109
Nomi, J. S., Rhodes, M. G., \& Cleary, A. M. (2013). Emotional facial expressions differentially influence predictions and performance for face recognition. Cognition and Emotion, 27, 141-149.

Price, J., \& Harrison, A. (2017). Examining what prestudy and immediate judgments of learning reveal about the bases of metamemory judgments. Journal of Memory and Language, 94, 177-194.

Price, J., McElroy, K., \& Martin, N. J. (2016). The role of font size and font style in younger and older adults' predicted and actual recall performance. Aging, Neuropsychology, and Cognition, 23, 366-388.

Ryan, E. B. (1992). Beliefs about memory changes across the adult life span. Journal of Gerontology, 47, 41-46.

Ryan, E. B., \& See, S. K. (1993). Age-based beliefs about memory changes for self and others across adulthood. Journal of Gerontology, 48, 199-201.

Su, N., Li, T., Zheng, J., Hu, X., Fan, T., \& Luo, L. (2018). How font size affects judgments of learning: Simultaneous mediating effect of item-specific beliefs about fluency and moderating effect of beliefs about font size on memory. PLOS ONE, 13, e0200888:1-14. doi: https://doi.org/10.1371/journal.pone.0200888

Susser, J. A., Jin, A., \& Mulligan, N. W. (2016). Identity priming consistently affects perceptual fluency but only affects metamemory when primes are obvious. Journal of Experimental Psychology: Learning, Memory, and Cognition, 42, 657-662.

Susser, J. A., \& Mulligan, N. W. (2015). The effect of motoric fluency on metamemory. Psychonomic Bulletin \& Review, 22, 1014-1019. doi: https://doi.org/10.3758/s13423-014-0768-1

Tauber, S. K., \& Dunlosky, J. (2012). Can older adults accurately judge their learning of emotional information? Psychology and Aging, 27, 924-933.

Tauber, S. K., Dunlosky, J., Urry, H. L., \& Opitz, P. C. (2016). The effects of emotion on younger and older adults' monitoring of learning. Aging, Neuropsychology, and Cognition, 24, 555-574.

Tullis, J. G., \& Fraundorf, S. H. (2017). Predicting other's memory performance: The accuracy and bases of social metacognition. Journal of Memory and Language, 95, 124-137.

Undorf, M., \& Erdfelder, E. (2015). The relatedness effect on judgments of learning: A closer look at the contribution of processing fluency. Memory \& Cognition, 43, 647-658.

Undorf, M., \& Zimdahl, M. F. (2019). Metamemory and memory for a wide range of font sizes: What is the contribution of perceptual fluency? Journal of Experimental Psychology: Learning, Memory, and Cognition, 45, 97-109. doi:https://doi.org/10.1037/ $\mathrm{x} \operatorname{lm} 0000571$

Undorf, M., Zimdahl, M. F., \& Bernstein, D. M. (2017). Perceptual fluency contributes to effects of stimulus size on judgments of learning. Journal of Memory and Language, 92, 293-304.

Witherby, A. E., \& Tauber, S. K. (2017). The concreteness effect on judgments of learning: Evaluating the contributions of fluency and beliefs. Memory \& Cognition, 45, 639-650.

Witherby, A. E., \& Tauber, S. K. (2018). Monitoring of learning for emotional faces: How do fine-grained categories of emotion influence participants' judgments of learning and beliefs about memory? Cognition and Emotion, 32, 860-866.

Yang, C., Huang, T. S.-T., \& Shanks, D. R. (2018). Perceptual fluency affects judgments of learning: The font size effect. Journal of Memory and Language, 99, 99-110.

Zimmerman, C. A., \& Kelley, C. M. (2010). "I'll remember this!": Effects of emotionality on memory predictions versus memory performance. Journal of Memory and Language, 62, 240-253. doi: https://doi.org/10.1016/j.jml.2009.11.004 